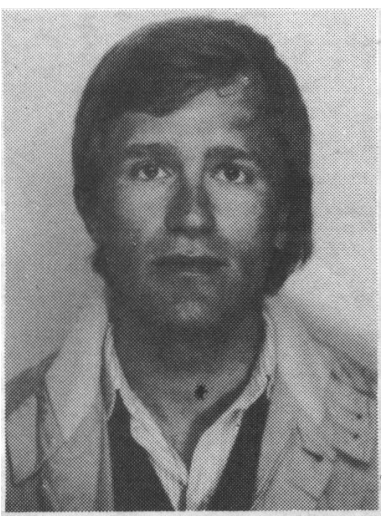

U. Jorgensen

\section{EPIDEMIOLOGY OF INJURIES IN TYPICAL SCANDINAVIAN TEAM SPORTS}

\author{
U. JØRGENSEN, MD \\ Department of Orthopaedic Surgery T3.K.A.S., Gentofte, Faculty of Medicine, \\ University of Copenhagen, 2600 Hellerup, Denmark
}

An investigation by questionnaire was undertaken in a group of $\mathbf{4 8 0}$ football players and 288 handball players (768 players). Of these 803 were injured, giving a player incidence of 4.1 injury/1000 football hours and 8.3 injury/1000 handball hours.

The lower extremities were involved in $82 \%$ of the football injuries, whereas handball injuries were evenly distributed on both upper and lower extremities.

The football injury prevalence was $\mathbf{0 . 3 6}$ per player, the handball injury prevalence 0.71 per player.

Medical attention was given to $62 \%$ of the injured footballers and $47 \%$ of the injured handballers.

Based on the injury pattern, some modifications to the rules and equipment in the two sports is suggested:

1. The "boot-type" footwear should be tried out, and the soles in both games should correspond to the different playing surfaces that may be encountered.

2. Stricter enforcement of the rules, and the use of a maximum size playing ground in both sports.

3. Last, but not least a modification of the football rules concerning substitution is a must.

Key words: Sports injury epidemiology, Football, Handball, Prophylaxis.

\section{INTRODUCTION}

The two most popular team sports in Scandinavia are football and European type handball. Both are contact sports, in which the results defined by goal scores are based upon a combination of technique, tactics, mentality, physique and last but not least unity.

League football is played outdoors in all kinds of weather, mainly on grass fields, measuring 90-100 metres by 45-90 metres, with goals. There are two linesmen, one referee and 22 players on the field plus 1.3 substitutes for each team. A substituted player must not enter the game again. The playing time is $2 \times 45$ minutes. Shin guards are compulsory. The footwear is mainly leather shoes with at least 6 studs, or none at all.

Cup handball is played on indoor courts with wooden or linoleum floors. The court measures $38-44$ by $18-22$ metres. There are 2 referees, 14 players and 5 substitutes on the bench. The team can exchange players from the field with reserves as often as they want.

There are no compulsory protective accessories, some, however, use knee and elbow pads, the thickness of which varies.

The footwear is of leather or canvas, but with a sole of different material (such as rubber, pvc, etc.). The sole can be grooved, checked or with hollowed circles, the friction is extremely variable. In handball the playing time is $\mathbf{2}$ halves of $\mathbf{3 0}$ minutes.

Often, the same people play both handball and football. Most of the handball players have played football 
and vice versa, since both games are played at school and the fitness training for each is almost identical (apart from the playing situations). I have found it interesting to study the incidence, prevalence and medical attention of injuries in Danish men's élite handball and football.

\section{MATERIAL AND METHOD}

The study is based upon questionnaires sent out through the DBU (Danish football association) and DHF (Danish handball association) at the end of the 1981/82 season and represents the injuries during a period of 1 season, which is $\mathbf{4 0}$ weeks/year in handball and $\mathbf{4 6}$ weeks/year in football.

An injury is defined as follows, "An injury received in connection with the game or in training in the club, which handicaps you during the game and/or requires special treatment (i.e. special bandaging or medical attention) in order to play, or completely prevents you from playing".

The individual players in the 1st team group (consisting of an average of 16 players in football and 12 in handball at the beginning of the season) completed themselves the questionnaires in the final week of the tournament after uniform briefing.

Danish élite football consists of a 1st division, a 2nd division and a 3rd division each of 16 teams making a total of 768 players.

Danish élite handball consists of one 1st division, two 2nd divisions and four 3rd divisions, making a total of 1008 players.

In this study a homogeneous and representative group was selected, players being from similar leagues, position in the team and age. There were $\mathbf{4 8 0}$ of football players and 288 handball players, making a total of 768 . The average age was 23.2 years (17-35) in football and 24.1 years (17-37) in handball. The number of weekly training and game hours were in football 7.2 hours (4$10)$ and in handball 4.1 hours (2.5-7.5).

Fischer's exact test and T-test with a significant level of $95 \%$ were used as statistic methods.

\section{RESULTS}

Replies were received from $383(79 \%)$ of the football players and $207(72 \%)$ of the handball players representing a typical, homogeneous group.

The number of injuries was 803 in all, 521 in football and 282 in handball. This presents an injury incidence made up in injuries per player/year to 1.54 in football and $\mathbf{1 . 7 7}$ in handball, or a player incidence of 4.1 injuries per 1000 football hours and 8.3 per 1000

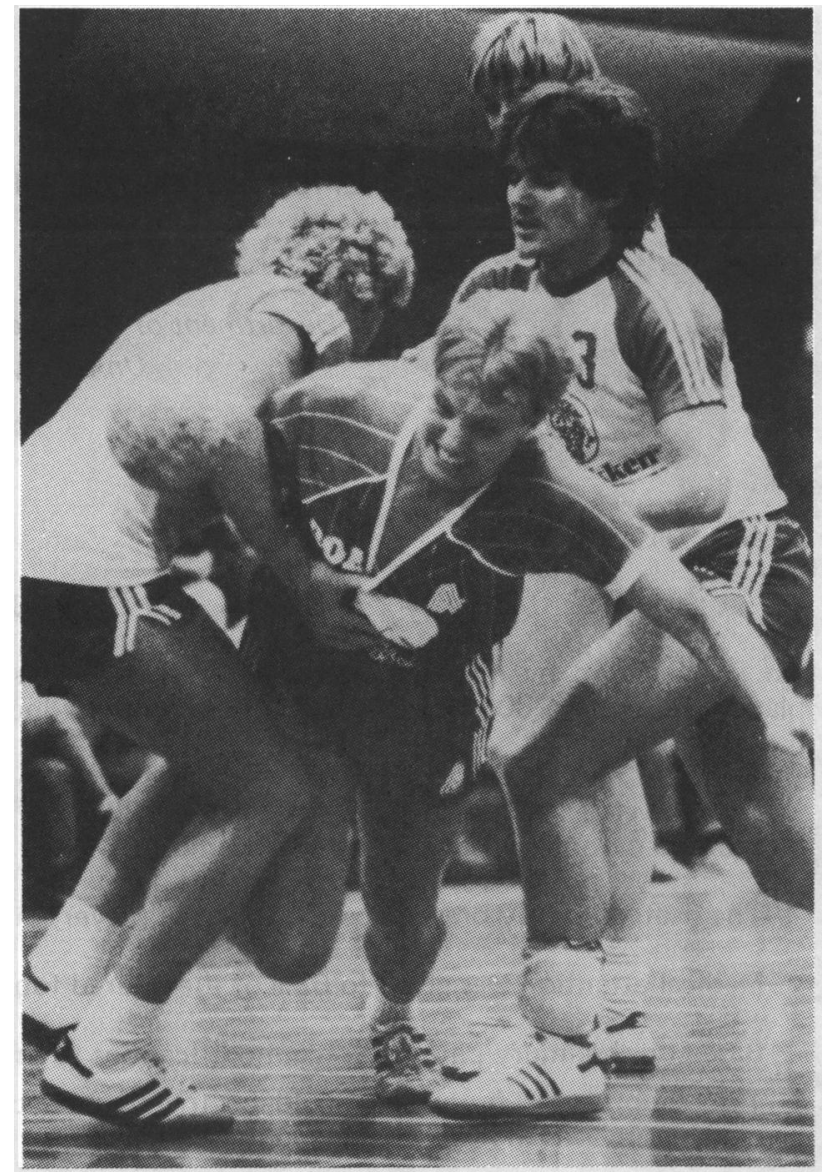

Safety equipment is not used by everyone.

handball hours, with an average of 321 football hours and 164 handball hours a year.

\section{THE PATTERN OF FOOTBALL INJURIES}

As can be seen in Table $\mathrm{I}$, injuries to the lower extremities are clearly predominant in football. They amount to $82 \%$ of all football injuries; most frequent are foot/ankle injuries making a total of approximately $25 \%, 23 \%$ are ankle sprains.

The second most frequent injury is muscular strain $(15 \%)$, then knee injuries $(14 \%)$ and inguinal injuries (12\%). Hand, finger and shoulder injuries are very rare in football.

\section{SPECIAL CHARACTERISTICS}

Goal keepers and defenders had an injury incidence significantly larger than that of the attackers. The age group of 26-29 had the significantly largest injury incidence, while the 30-33-year-olds had a muscular strain incidence that was twice as big as that of the rest 


\section{TABLE I}

The injury pattern in football (soccer), (355 players) and the number of injuries getting medical attention.

$\begin{array}{lrrr}\text { Injury types } & \text { Number } & \% & \begin{array}{c}\text { Medical attention } \\ \text { (\% of the injury type) }\end{array} \\ \text { Foot/ankle } & 132 & 25 & 50 \\ \text { Knee } & 71 & 14 & 73 \\ \text { Leg muscle strains } & 80 & 15 & 52 \\ \text { Leg muscle contusions } & 51 & 10 & 30 \\ \text { Inguinal injuries } & 63 & 12 & 68 \\ \text { Skin tears } & 32 & 6 & 91 \\ \text { Fractures } & 24 & 5 & 100 \\ \text { Dislocations } & 11 & 2 & 27 \\ \text { Back pain } & 10 & 2 & 0 \\ \text { Achilles tendon lesions } & 5 & 1 & 0 \\ \text { Finger/hand } & 5 & 1 & 0 \\ \text { Others } & 37 & 8 & 0 \\ \text { Total } & 521 & 100 & 62 \%\end{array}$

of the groups. Rotation on a fixed foot was causing many of the more serious twists, which particularly affected knees and ankles. Offences caused or were associated with $25 \%$ of the injuries.

\section{THE PATTERN OF HANDBALL INJURIES}

The injuries in handball (Table II) were evenly distributed in both the upper and lower extremities. Most frequent were injuries of the hand and fingers (29\%), foot/ankle (16\%) and knee injuries (10\%).

Muscular strains and contusions made up $18 \%$ in the lower extremities and $4 \%$ in the upper extremities.

\section{TABLE II}

The injury pattern in European type handball (207 players) and the number of injuries getting medical attention.

$\begin{array}{lrrc}\text { Injury pattern } & \text { Number } & \% & \begin{array}{c}\text { Medical attention } \\ \text { (\% of the injury type) }\end{array} \\ \text { Foot/ankle } & 45 & 16 & 62 \\ \text { Knee } & 25 & 9 & 80 \\ \text { Leg muscle/tendon } & 52 & 18 & 23 \\ \text { Finger } & 64 & 23 & 49 \\ \text { Hand (- fingers) } & 17 & 6 & 27 \\ \text { Elbow } & 18 & 6 & 55 \\ \text { Shoulder } & 23 & 8 & 70 \\ \text { Arm muscle/tendon } & 11 & 4 & 45 \\ \text { Back pain } & 7 & 3 & 43 \\ \text { Others } & 20 & 7 & 50 \\ \text { Total } & 282 & 100 & 53 \%\end{array}$

\section{SPECIAL CHARACTERISTICS}

The back players had significantly more injuries than the goal keepers and the line players. Typical were shoulder injuries among the back players, knee injuries for the line players and elbow injuries for the goal $\overrightarrow{0}$ keepers. It was remarkable that knee injuries among $\frac{0}{0}$ line players very often happened along with twists on a क fixed foot.

Most of the injuries happened in connection with is offensive play and approx. $20 \%$ of the injuries were due to fouls.

\section{PREVALENCE}

In football at the time of the study, there was 0.36 injuries per player, i.e. every 3 rd player was injured. $\vec{\infty}$ 27\% played in spite of an injury. In handball there was $i$ 0.71 injuries per player, i.e. more than half of the $\mathcal{G}$ players were injured. $55 \%$ of the total number of players $\frac{}{3}$ played in spite of the injury.

In football 127 were injured, 25 of these were unable to play, (Table III). The most frequent injuries to be played with, were foot and ankle injuries $(32 \%)$, next were groin injuries, muscular sprains and Achilles tendon lesions, the three making a total of $32 \%$. Knee injuries were the most frequent reason for football players being unable to play, $(52 \%)$.

\section{TABLE III}

The prevalence of injuries in football (soccer)

$\begin{array}{lccc}\text { Injury types } & \begin{array}{c}\text { Total } \\ \text { number }\end{array} & \text { Playing } & \begin{array}{c}\text { Unable } \\ \text { to play }\end{array} \\ \text { Foot/ankle } & 38 & 33(32 \%) & 5 \\ \text { Knee } & 33 & 20 & 13(52 \%) \\ \text { Inguinal } & 18 & 17 & 1 \\ \text { Muscle strains (leg) } & 8 & 7 & 1 \\ \text { Achilles tendon lesions } & 10 & 8 & 2 \\ \text { Fractures (lower limb) } & 3 & 0 & 3 \\ \text { Upper limbs } & 7 & 7 & 0 \\ \text { Others } & 10 & 10 & 0 \\ \text { Total } & 127 & 102 & 25\end{array}$

In handball 148 were injured. Of these, 112 played on (Table IV) however, with injuries mainly located in the upper extremities, both those in which the player 0 continued his game $(33.9 \%)$ and in those who had to $\Phi$ lay off $(36 \%)$. The player prevalence was 0.71 injuries per player.

If a handball player was injured during the game, he was replaced immediately, while $80 \%$ of the football players had to stay on the field despite an injury because the substitute had already been used. Of these $30 \%$ were 


\section{TABLE IV}

The prevalence of injuries in European type handball.

$\begin{array}{lrrr}\text { Injury type } & \text { Total number } & \text { Playing } & \text { Unable to play } \\ \text { Foot/ankle } & 15 & 10 & 5 \\ \text { Knee } & 16 & 14 & 2 \\ \text { Leg muscle/tendon } & 20 & 16 & 3 \\ \text { Finger/hand } & 51 & 38 & 13 \\ \text { Arm others } & 38 & 29 & 9 \\ \text { Other injuries } & 8 & 7 & 1 \\ \text { Total } & 148 & 112 & 36\end{array}$

sure that the injury had become worse because they had to stay in the game.

\section{MEDICAL ATTENTION}

Of all football injuries $62 \%$ were seen by a physician, mainly knee injuries which were very often attended by several different physicians. However, foot and ankle injuries were only seen in $50 \%$ of the incidents. One injury in ten was treated by a zone therapist. Only $49 \%$ of the division clubs had a permanent team physician (Table I).

Half of the handball injuries $(47 \%)$ were attended by a physician. The injuries that most frequently received no medical attention were finger/hand injuries, muscle contusions and strains, plus shoulder and elbow injuries. $80 \%$ of the knee injuries and $62 \%$ of the foot/ankle injuries were, however, attended (Table II).

\section{DISCUSSION}

This study is for practical reasons planned in 'Enquete' form, as the purpose was an optimum registration of injuries. The form has proved to be fairly precise (Andrèn-Sandberg et al, 1981) and with few known sources of error (Ritzer, 1977).

The definition of an injury (which was not limited as regards the time prevalence) opens, contrary to others such as Renström and Peterson (1977) a possibility of disclosure of the injuries being played with, and not only those who had to leave the field. However, inter-personal differences have to be taken in to account.

The injury incidence is $\mathbf{1 . 3 6}$ injuries/season per player in handball and football. In the unit of injuries per player/year it is $\mathbf{1 . 5 4}$ in football and $\mathbf{1 . 7 7}$ in handball or as injuries per 1000 playing hours it is 4.1 in football and $\mathbf{8 . 3}$ in handball. As the injury incidence and pattern change along with training time and number of games (Ekstrand, 1982) the two last mentioned ratios can only be regarded as figures of the potential risk of exposure. According to this the risk of being injured is twice as big in handball as in football. This fact may be explained by the constant close-contact play on the smaller handball court.

With different definitions and material and consequently other injury incidences, others have particularly tried to elucidate the epidemiology of football injuries. In this way Ekstrand (1982) finds an incidence of 7.6 \pm 2.1 per 1000 training hours and $16.9 \pm 7.3$ per 1000 game hours by studying Swedish 4th division players (approx. 130 football hours a year). Renström and Peterson (1977) find, that 8 players per year per football team were injured in a broad spectrum of clubs at different playing levels. Andrèn-Sandberg and Linstrand (1982) find in an examination of handball injuries attended by doctors that knee injuries are the biggest problem, but they state no incidence.

The pattern of injuries in this study is dominated by leg injuries $(82 \%$ of the football injuries and $50 \%$ of the handball injuries). Pathophysiologically, twists of knee and ankles dominate.

In football the sole of the boot has a decisive influence on the injury pattern (Renström and Peterson, 1977). Since a football boot with safety bindings has not been invented yet, focus is on the number and type of studs, their size and position, but not on the shape of the football boot and thus the possibility of external ankle stabilisation is being investigated. Prophylactic taping of ankles is recommended by many people (Ekstrand, 1982). Anyway, this is a possibility in handball where the high basketball boot has not become popular. Few have, however, thought of the friction between handball shoes and the changing material of the floor, which is an obvious factor in injury causation and consequently an object of prophylaxis.

Players should therefore use handball shoes with soles that correspond to the different surfaces of the floor (for instance linoleum and wooden floors with different finish), (Menck and Jørgensen, 1983).

The numerous contusions could definitely be reduced by more strict enforcement of the rules in both handball and football. It is difficult to estimate the value of the two-referee system used in handball, but it could possibly reduce the number of injuries in football if the system was introduced here as fouls were actually the cause of $25 \%$ of the injuries in football and $20 \%$ in handball.

The value of compulsory safety equipment can be estimated only with difficulty; it is, however, obvious that for instance special stuffed elbow pads for goal keepers in handball were a possibility. Furthermore, stuffed knee protectors could be suggested, especially for line players. 
Finger and hand injuries in handball are a built-in risk in the game but ordinary prophylactic taping is a possibility, which is not directly compatible with the maximum ball control that the player wants. If, on the other hand a tape with a rugged, slightly sticky surface was available it would perhaps become popular in the game.

The differences in size of handball and football grounds together with the potential injury risk may tempt one to recommend a utilisation of the allowed maximum size of both grounds, for prophylactic purposes. This will, however, demand further studies as it may influence the injury pattern as well.

The prevalence of injuries shows that $36 \%$ of the football players and $71 \%$ of the handball players were injured. This is suggestive, as $27 \%$ of the football players and $55 \%$ of the handball players played in spite of these injuries. The potential sequelae and the fact, that the risk of a major injury is great within the first three months after having received a minor injury (Ekstrand, 1982) turns it into a very important area. The problem does not get smaller as $38 \%$ of the football injuries and $53 \%$ of those in handball are not attended by a physician.

All the injured handball players were free to leave the field and did so to a large extent, while, indirectly because of the changing-rules, $80 \%$ of the football players had to stay in the game, which meant running an unnecessary risk of prolonging the degree and duration of the injury, a fact which should lead to a modification of the rules concerning substitution.

When thinking of how many people play handball and especially football, small modifications of the rules as suggested would produce a great socioeconomical importance without influencing the quality of the game; if anything, on the contrary.

\section{REFERENCES}

Andrèn-Sandberg et al, 1981 "Low injury risk in European type handball. Knee injuries the biggest problem". Lakaratidningen.V.78.49: 4444-4445.

Andrèn-Sandberg, A. and Lindstrand, A., 1982 "Injuries sustained in junior league handball. A prospective study of validity in the registration of sports injuries". Scand.J.Soc.Med. 10 (3): 101-4.

Ekstrand, J., 1982 "Soccer injuries and their prevention". Lindköping University Medical Dissertations No. 130. Lindköping.

Menck, H. and Jørgensen, U., 1983 "Frictional forces and ankle fractures in sport". Brit.Journ.Sports Med. 17: 135-136.

Renström, P. and Peterson, L., 1977 “Frekvens och art av fotbolls-skåder i Göteborg.1: Fotbollsplan på konstgräs. Naturvardsverket SNV PM 846.

Ritzer, G., 1977 “Fundementale perspektiver i sociologien”. Fremad, Copenhagen: 75-88. 